\title{
The risk factors of gestational hypertension in patients with polycystic ovary syndrome: a retrospective analysis
}

\author{
Shu Zhou', Yiping $\mathrm{Ji}^{2^{*}}$ and Haimei Wang ${ }^{3^{*}}$
}

\begin{abstract}
Background: The hypertensive disorders complicating pregnancy (HDCP) is common in patients with polycystic ovary syndrome (PCOS), yet the potential influencing factors remained unclear. We aimed to assess the independent risk factors of HDCP in patients with PCOS, to provide clinical evidences for the management of PCOS.

Methods: Pregnant PCOS patients treated in our hospital from June 1, 2018 to November 30, 2020 were approached. The personal and clinical characteristics of patients with and without gestational hypertension were evaluated. Logistic regressions were conducted to identify the independent risk factors of HDCP, Receiver operating characteristics (ROC)curve analysis was conducted to evaluate the predicting value.

Results: A total of 188 PCOS patients were included, the incidence of HDCP in patients with PCOS was $27.66 \%$. There were significant differences in the age, BMI, family history of hypertension, the history of adverse pregnancy, history of contraceptive pills use and family history of HDCP between HDCP group and no-HDCP group (all $p<$ 0.05), and there were no significant differences in the family history of diabetes, multiple pregnancy and long-term smoking history between HDCP group and no-HDCP group (all $p>0.05$ ). Age $\geq 27 y($ OR2.048, $95 \%$ Cl1.121 3.208), $\mathrm{BMI} \geq 24 \mathrm{~kg} / \mathrm{m}^{2}$ (OR1.463, $95 \% \mathrm{Cl} 1.069 \sim 2.011$ ), family history of hypertension(OR2.129, $\left.95 \% \mathrm{Cl} 1.093 \sim 3.042\right)$, the history of adverse pregnancy(OR2.435, $95 \%$ Cl1.264 4.085), history of contraceptive pills use(OR3.806, $95 \%$ Cl1.184 6.102), family history of HDCP(OR1.934, $95 \% \mathrm{Cl} 1.016$ 2.774) were the independent risk factors of HDCP in patients with PCOS (all $p<0.05$ ). ROC curve analyses indicated that those factors had good predictive value on HDCP in PCOS patients.

Conclusions: The incidence of HDCP in PCOS patients is relatively high. In clinical practice, medical workers should carry out early prevention and intervention measures for these risk factors to reduce the incidence of HDCP.
\end{abstract}

Keywords: Hypertension, Pregnancy, Polycystic ovary syndrome, Prevention, Care

\footnotetext{
* Correspondence: 329176068@qq.com; haimeiwang@tom.com

${ }^{2}$ Department of gynaecology, Lian Shui county People's Hospital, Huai'an,

China

${ }^{3}$ Department of Urology, The Affiliated Huai'an Hospital of Xuzhou Medical University and The Second People's Hospital of Huai'an, No.62, Huaihai Road, Jiangsu 223002 Huai'an, China

Full list of author information is available at the end of the article
}

(c) The Author(s). 2021 Open Access This article is licensed under a Creative Commons Attribution 4.0 International License, which permits use, sharing, adaptation, distribution and reproduction in any medium or format, as long as you give appropriate credit to the original author(s) and the source, provide a link to the Creative Commons licence, and indicate if changes were made. The images or other third party material in this article are included in the article's Creative Commons licence, unless indicated otherwise in a credit line to the material. If material is not included in the article's Creative Commons licence and your intended use is not permitted by statutory regulation or exceeds the permitted use, you will need to obtain permission directly from the copyright holder. To view a copy of this licence, visit http://creativecommons.org/licenses/by/4.0/ The Creative Commons Public Domain Dedication waiver (http://creativecommons.org/publicdomain/zero/1.0/) applies to the data made available in this article, unless otherwise stated in a credit line to the data. 


\section{Background}

Polycystic ovary syndrome (PCOS) is one of the most common endocrine disorders in women of childbearing age, and it is also the main cause of anovulatory infertility [1]. PCOS is mainly manifested by menstrual disorders, hirsutism, infertility, and hyperandrogenism [2]. The prevalence of PCOS ranges from 5.11 to $10.08 \%$, which is related to different races, populations, regions, and diagnostic criteria [3, 4]. Previous studies [5, 6] have found that PCOS patients are prone to insulin resistance, hyperinsulinemia, cardiovascular disease, metabolic syndrome, sleep apnea, and hypertension during pregnancy. Currently, the pathogenesis of PCOS has not yet been fully elucidated [7]. Therefore, the prevention and treatment of PCOS is on the top research agenda of medical staff.

Hypertensive disorders complicating pregnancy (HDCP) especially the gestational hypertension is one of the common complications that are unique to pregnancy, and its specific pathogenesis is currently unclear, which can lead to a variety of adverse pregnancy outcomes and seriously harm the health of mothers and children [8]. It often occurs in the middle and late stages of pregnancy [9]. The blood pressure of patients during pregnancy continues to be higher than the upper limit of normal, which causes greater damage to multiple organs of the pregnant woman, but the specific cause is still unclear [10]. Many studies [11-13] believe that age, prepregnancy BMI, changes in blood viscosity, reduction in platelet count and other related risks have a significant role in promoting the occurrence of HDCP. Pregnancy is a dynamic development process, and the basic physical condition of pregnant women in early pregnancy and the influence of related factors during pregnancy can all lead to the occurrence of HDCP [14]. To this end, this study aimed to analyze the independent risk factors of HDCP in patients with PCOS, to provide evidence support for the prevention of HDCP in patients with PCOS, to improve the prognosis of PCOS patients.

\section{Methods}

Our study was a retrospective study design, and it had been checked and approved by the ethical committee of The Affiliated Huai'an Hospital of Xuzhou Medical University $($ No.18,020,277), and all the included patients had been well-informed and agreed to participant in this study, written informed consents had been obtained from all the patients. We tried to conduct and report this study according to related guidelines.

\section{Patients}

We retrospectively selected the pregnant PCOS patients who were diagnosed and treated in our hospital from June 1, 2018 to November 30, 2020 as the research populations, the patients were selected from the antenatal department of our hospital. The inclusion criteria for this study were: those pregnant patients who underwent gestational hypertension screening in our hospital ; the diagnosis of PCOS met the relevant diagnostic criteria [15, 16]: (1)rare ovulation or anovulation; (2)clinical manifestations of hyperandrogen and (or) hyperandrogenemia; (3)ovarian polycystic changes. PCOS was diagnosed when two of the previous three items are met, and the PCOS were confirmed through the lab pathology results and ultrasound. The patients were wellinformed and agreed to participate in this study. The exclusion criteria of this study were: PCOS patients with previous tumors, rheumatic immune diseases, blood system and other diseases, and those with incomplete clinical data; the patients with chronic hypertension, fertility treatment; patients who do not agree to participate in this study.

\section{HDCP diagnosis}

According to the HDCP diagnosis and treatment guideline [17] formulated by the HDCP Group of the Chinese Medical Association Obstetrics and Gynecology Branch, the gestational hypertension was diagnosed as follows: hypertension occur for the first time after 20 weeks of pregnancy, systolic blood pressure $\geq 140 \mathrm{mmHg}$ and/or diastolic blood pressure $\geq 90 \mathrm{mmHg}$, returned to normal within 12 weeks after delivery; meanwhile, urine protein test was negative.

\section{Data collection}

We reviewed and collected relevant medical data of patients undergoing prenatal check-ups in our hospital. The prenatal examinations in our hospital mainly include B-ultrasound to determine whether it is a normal intrauterine pregnancy and determine the gestational age; screening of unhealthy lifestyles, such as whether pregnant women smoke, drink, illegally use drugs, inject drugs, etc.; blood and urine routines and liver and kidney function analysis. cervical cytology; screening for Down syndrome. Two authors independently collected the personal and clinical characteristics of included PCOS patients through the medical records, including age, the booking body weight for body mass index (BMI), family history of hypertension, family history of diabetes, the history of adverse pregnancy, multiple pregnancy, history of contraceptive pills use, long-term smoking history, family history of HDCP.

\section{Statistical processing}

We used SPSS 23.0 software for statistical analysis of relevant data. The measurement data was expressed by $\mathrm{t}$ test and expressed as mean \pm standard deviation $(\mathrm{x} \pm \mathrm{s})$; the count data was expressed by $\mathrm{x} 2$ test and expressed 
by frequency(\%). KS test was conducted to test the normality of analyzed outcomes, conditional mean completer method was performed to analyze the missing data. The variates with positive results in the univariate analysis were further included for logistic regression to identify the independent risk factors of HDCP, Receiver operating characteristics (ROC)curve analysis was conducted by PRISE Software package, and Youden index was calculated by the software. $P<0.05$ indicated that the difference was statistically significant.

\section{Results}

\section{Included patients}

215 women's medical record were initially screened, 27 patients were excluded because some of the personal characteristics were missing. Finally, a total of 188 PCOS patients were included, of whom 52 patients had been diagnosed as HDCP, the incidence of HDCP in patients with PCOS was $27.66 \%$. As presented in Table 1, there were significant differences in the age, BMI, family history of hypertension, the history of adverse pregnancy, history of contraceptive pills use and family history of HDCP between HDCP group and no-HDCP group (all $p<0.05)$, and there were no significant differences in the family history of diabetes, multiple pregnancy and longterm smoking history between HDCP group and noHDCP group (all $p>0.05$ ).

\section{The risk factors of HDCP in patients with PCOS}

Table 2 presented the variable assignment of multivariate logistic regression. And as indicated in Table 3, Age $\geq 27 \mathrm{y}(\mathrm{OR} 2.048,95 \% \mathrm{CI} 1.121 \sim 3.208), \mathrm{BMI} \geq 24 \mathrm{~kg} /$ $\mathrm{m}^{2}$ (OR1.463, $95 \% \mathrm{CI} 1.069 \sim 2.011$ ), family history of hypertension(OR2.129, $95 \% \mathrm{CI} 1.093 \sim 3.042)$, the history of adverse pregnancy(OR2.435, $95 \% \mathrm{CI} 1.264 \sim 4.085)$, history of contraceptive pills use(OR3.806, $95 \% \mathrm{CI} 1.184$ 6.102), family history of HDCP(OR1.934, $95 \%$ CI1.016 $\sim 2.774$ ) were the independent risk factors of HDCP in patients with PCOS (all $p<0.05$ ).
Table 2 The variable assignment of multivariate logistic regression

\begin{tabular}{lll}
\hline Factors & Variables & Assignment \\
\hline HDCP & $Y$ & yes $=1, \mathrm{no}=2$ \\
Age $(\mathrm{y})$ & $X_{1}$ & $\geq 27=1,<27=2$ \\
$\mathrm{BMI}\left(\mathrm{kg} / \mathrm{m}^{2}\right)$ & $X_{2}$ & $\geq 24=1,<24=2$ \\
Family history of hypertension & $X_{3}$ & yes $=1, \mathrm{no}=2$ \\
The history of adverse pregnancy & $X_{4}$ & yes $=1, \mathrm{no}=2$ \\
History of contraceptive pills use & $X_{5}$ & yes $=1, \mathrm{no}=2$ \\
Family history of HDCP & $X_{6}$ & yes $=1, \mathrm{no}=2$ \\
\hline
\end{tabular}

\section{The ROC analysis}

The ROC curve on the risk factors predicting the HDCP in PCOS patients was presented in Fig. 1. As presented in Table 4 , age $\geq 27 y, B M I \geq 24$, family history of hypertension, the history of adverse pregnancy, history of contraceptive pills use and family history of HDCP had good predictive value with good sensitivity and specificity for predicting the HDCP in PCOS patients.

\section{Discussions}

PCOS has a high incidence in countries around the world. Epidemiological studies [18-20]have reported that $30 \%$ of women of childbearing age with abnormal BMI have the occurrence of PCOS. At the same time, the disease is also accompanied by a variety of metabolic-related diseases, which affect the whole body. Moreover, it has a certain promoting effect on other diseases such as endometrial cancer and hypertension during pregnancy [21]. The specific mechanism of PCOS is still not very clear. Some studies $[8,22,23]$ believe that the occurrence of the disease is related to environmental factors. Various factors act to activate related signaling pathways, which in turn leads to abnormalities in various metabolic pathways, but metabolic abnormalities are related to the occurrence of PCOS. However, the connection between them is still unclear. Therefore, it is

Table 1 The characteristics of included PCOS patients

\begin{tabular}{|c|c|c|c|c|}
\hline Variables & $\operatorname{HDCP} \operatorname{group}(n=52)$ & No-HDCP group $(n=136)$ & $t / x^{2}$ & p \\
\hline Age(y) & $28.81 \pm 8.11$ & 25. $05 \pm 8.46$ & 1.761 & 0.027 \\
\hline $\operatorname{BMI}\left(\mathrm{kg} / \mathrm{m}^{2}\right)$ & $24.97 \pm 2.03$ & $22.94 \pm 1.89$ & 1.024 & 0.021 \\
\hline Family history of hypertension & $37(71.15 \%)$ & $25(18.38 \%)$ & 1.291 & 0.035 \\
\hline Family history of diabetes & $10(19.23 \%)$ & $27(19.85 \%)$ & 1.744 & 0.092 \\
\hline The history of adverse pregnancy & $28(53.85 \%)$ & $14(10.29 \%)$ & 1.607 & 0.017 \\
\hline Multiple pregnancy & $9(17.30 \%)$ & $26(19.12 \%)$ & 1.812 & 0.069 \\
\hline History of contraceptive pills use & $25(48.08 \%)$ & $25(18.38 \%)$ & 1.097 & 0.016 \\
\hline Long-term smoking history & $6(11.54 \%)$ & $16(11.76 \%)$ & 1.182 & 0.083 \\
\hline Family history of HDCP & $30(57.69 \%)$ & $22(16.18 \%)$ & 1.201 & 0.006 \\
\hline
\end{tabular}


Table 3 Logistic regression analysis on the risk factors of HDCP in patients with PCOS

\begin{tabular}{llllll}
\hline Variables & B & Wald & OR & 95 \%Cl & p \\
\hline Age $\geq 27 y$ & 0.158 & 12.129 & 2.048 & $1.121 \sim 3.208$ & 0.042 \\
BMI $\geq 24$ & 0.122 & 7.199 & 1.463 & $1.069 \sim 2.011$ & 0.025 \\
Family history of hypertension & 0.101 & 18.115 & 3.099 & 2.435 & $1.093 \sim 3.042$ \\
The history of adverse pregnancy & 0.186 & 17.173 & 3.806 & $1.264 \sim 4.085$ & 0.025 \\
History of contraceptive pills use & 0.123 & 9.102 & 1.934 & $1.184 \sim 6.102$ & $0.017 \sim 2.774$ \\
Family history of HDCP & 0.113 & & 0.041 \\
\hline
\end{tabular}

necessary to conduct further investigations on the mechanism and treatment strategies of PCOS.

HDCP is a special disease that occurs during pregnancy, with an incidence rate of about $9 \%$ in China, which is higher than that of being reported in other countries [5, 24]. HDCP is one of the five major causes of maternal death during pregnancy. It often manifests as transient hypertension, proteinuria, etc., and the above symptoms and signs will disappear after delivery [25]. At present, related studies [26-28] believe that the possible causes of the disease are immune system imbalance, shallow placental implantation, abnormal trophoblast cells invading the myometrium, damage to the endovascular screen cells, and genetic factors. The incidence of HDCP in women with PCOS is much higher than that of ordinary healthy women of childbearing age, which is related to endocrine disorders, obesity, insulin resistance, etc. in patients with PCOS [29, 30], but there are few relevant research reports and lack of related risks analysis. The results of our study have found that the incidence of HDCP in patients with PCOS was $27.66 \%$, and age $\geq 27 y, B M I \geq 24$, family history of hypertension, the history of adverse pregnancy, history of contraceptive pills use and family history of HDCP were the risk factors of HDCP in PCOS patients, PCOS patients with those risk factors should be highly alerted for HDCP.

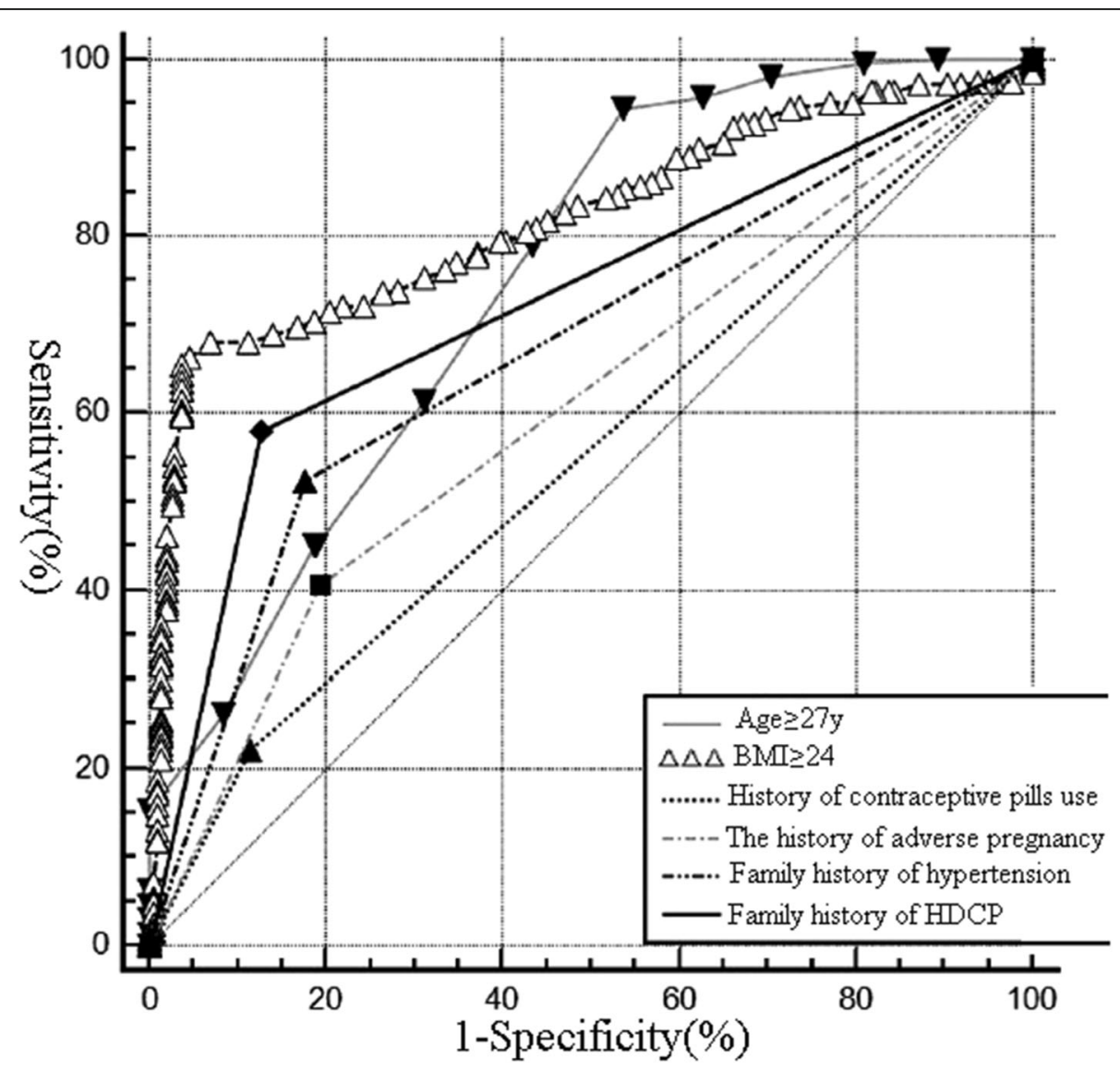

Fig. 1 The ROC curve on the risk factors predicting the HDCP in PCOS patients 
Table 4 The reference value of related risk factors for HDCP in patients with PCOS

\begin{tabular}{llccc}
\hline Variables & AUC & Yorden Index & Sensitivity & Specificity \\
\hline Age $\geq 27 y$ & 0.725 & 0.388 & $94.65 \%$ & $46.36 \%$ \\
BMI $\geq 24$ & 0.828 & 0.602 & $65.55 \%$ & $96.13 \%$ \\
Family history of hypertension & 0.681 & 0.375 & $52.63 \%$ & $83.24 \%$ \\
The history of adverse pregnancy & 0.607 & 0.227 & $40.18 \%$ & $81.51 \%$ \\
History of contraceptive pills use & 0.548 & 0.186 & $69.19 \%$ & $81.57 \%$ \\
Family history of HDCP & 0.701 & 0.447 & $58.02 \%$ & $86.98 \%$ \\
\hline
\end{tabular}

The ability of independent risk factors to predict HDCP is different. The highest AUC and highest specificity are seen in the BMI. Previous related studies[31, 32] have shown that abortion history and age are independent risk factors that affect the pregnancy outcome of patients with polycystic ovary syndrome, which is consistent with the conclusions of this study. Previous studies[33, 34] also have confirmed that BMI, age, family history of hypertension, etc. are independent risk factors that affect the onset of hypertension during pregnancy, which is also consistent with the findings of this study.

Many recent studies[35, 36] have found that insulin resistance is one of the pathogenesis of HDCP. Vascular artery smooth muscle cells and vascular endothelial cells are both insulin-sensitive cells. Vascular endothelial cells are activated under the stimulation of hyperinsulinemia and cause further damage. Nitric oxide production is reduced, while prostaglandin production is inhibited, and peripheral vascular resistance increase, eventually leading to increased blood pressure[37, 38]. In addition, hyperinsulinemia can also promote abnormal vascular smooth muscle cell proliferation, vascular endothelial dysfunction, vascular lumen stenosis, and increased vascular resistance[39]. Since most PCOS patients show lipid peroxidation and hyperlipidemia, this may also be one of the reasons for the damage of vascular endothelial cell function[40]. Pathophysiological studies have shown that insulin resistance plays a role in promoting the early stages of hypertension in pregnancy, such as vascular endothelial damage and hyperlipidemia, which may eventually lead to the development of hypertension in pregnancy[41, 42]. Previous study[43] has found that preeclampsia is significantly related to homocysteinemia and insulin resistance. It is speculated that the pathological mechanism may directly damage endothelial cells through mechanisms such as hypomethylation, oxidative stress, and endothelial cell dysfunction, resulting in abnormal vasomotor function, which may be associated with the development of HDCP[44-46].

For decades, measures have been taken to reduce the dosage and improve the formula for the adverse reactions caused by the use of contraceptives. However, recent studies $[47,48]$ have shown that the use of low-dose contraceptives can still increase blood pressure. It is currently believed that the increase in blood pressure is mainly related to estrogen, and its mechanism may be: estrogen has the possibility of water and sodium retention $[49,50]$. Estrogen can increase liver angiotensinogen. It is known that insulin resistance is closely related to hypertension, and estrogen can increase insulin resistance, which may be related to increased blood pressure. health screening for contraceptive users through training and guiding grassroots service personnel to implement informed choice of contraceptives and family planning follow-up services to prevent cardiovascular diseases in women, to improve the safety and efficiency of contraceptives[51, 52]. Meanwhile, it's necessary to carry out in-depth research on the safety of contraceptives to further clarify the relationship between contraceptives and hypertension.

Several limitations in this present study must be concerned. Firstly, we did not calculate the sample size, the sample size may be not large enough to use logistic regression analysis, and it may be underpowered to detect the potential differences, future studies with larger sample size are needed. Secondly, since our study is retrospective analysis, many laboratory results could not be included for data analysis since some of included patients missing the related data, there might be some differences in the laboratory results. Besides, the distribution of PCOS phenotypes remained unclear in this study. which needs further investigations in the future studies. Thirdly, oral contraceptive pills are among the first-line treatment for menstrual disturbances and clinical hyperandrogenism in PCOS. The doctors asked patients for history of contraceptive pills usage and recorded it in the medical record, the types and dosage of contraceptive pills usage in our study remained unclear, which might introduce biases, therefore the results should be treated with cautions.

\section{Conclusions}

In summary, we have found that the incidence of HDCP in patients with PCOS was rather high, and for PCOS patients with age $\geq 27 y, \quad B M I \geq 24$, family history of hypertension, the history of adverse pregnancy, history of contraceptive pills use and family history of HDCP, early alert for risk of HDCP development should be 
concerned, and associated preventions and treatments should be adopted to reduce the occurrence of HDCP. Obstetricians should provide education and guidance for PCOS patients before pregnancy, inform them of the risks of overweight or obesity during pregnancy, and take appropriate pre-pregnancy prevention measures, try to control the pre-pregnancy weight within the ideal range, avoid the adverse pregnancy, reduce the contraceptive pills use, strengthen pregnancy monitoring and screening, and formulate prevention and management measures to reduce the development of HDCP, to improve the maternal and child prognosis[53, 54]. However, the interrelationship between PCOS and HDCP and the underlying mechanisms are still unclear, which needs further investigations in the future.

\section{Abbreviations}

PCOS: Polycystic ovary syndrome; HDCP: Hypertensive disorders complicating pregnancy; BMI: Body mass index; ROC: Receiver operating characteristics

\section{Acknowledgements}

None.

\section{Authors' contributions}

S Z, H W designed research; S Z, Y J conducted research; S Z, H W analyzed data; H W wrote the first draft of manuscript; $Y \mathrm{~J}$ and $\mathrm{H}$ W had primary responsibility for final content. All authors read and approved the final manuscript.

\section{Funding}

None.

\section{Availability of data and materials}

All data generated or analyzed during this study are included in this published article.

\section{Declarations}

\section{Ethics approval and consent to participate}

Our study had been checked and approved by the ethical committee of The Affiliated Huai'an Hospital of Xuzhou Medical University (No.18020277), and all the included patients had been well informed and agreed to participant in this study, written informed consents had been obtained from all the patients. We tried to conduct and reported this study according to related guidelines.

\section{Consent for publication}

Not applicable.

\section{Competing interests}

The authors declare that they have no competing interests.

\section{Author details}

${ }^{1}$ Department of gynaecology, The 5th Affiliated Hospital of Nantong University (Taizhou People's Hospital), Taizhou, China. ${ }^{2}$ Department of gynaecology, Lian Shui county People's Hospital, Huai'an, China. ${ }^{3}$ Department of Urology, The Affiliated Huai'an Hospital of Xuzhou Medical University and The Second People's Hospital of Huai'an, No.62, Huaihai Road, Jiangsu 223002 Huai'an, China.

Received: 16 February 2021 Accepted: 15 April 2021

Published online: 27 April 2021

\section{References}

1. Barber TM, Franks S: Obesity and polycystic ovary syndrome. Clin Endocrinol (Oxf) 2021 3(2): 69-73.
2. Bjekic-Macut J, Vukasin T, Velija-Asimi Z, Burekovic A, Zdravkovic M, Andric Z, Brankovic M, Crevar-Marinovic S, Madic T, Stanojlovic O et al: Polycystic ovary syndrome: a contemporary clinical approach. Curr Pharm Des. 2021; 16:18-26.

3. Buyers E, Sass AE, Severn CD, Pyle L, Cree-Green M. Twelve-month continuation of the etonogestrel implant in adolescents with polycystic ovary syndrome. J Pediatr Adolesc Gynecol. 2021;34(1):33-9.

4. Valent AM, Barbour LA. Management of Women with Polycystic Ovary Syndrome During Pregnancy. Endocrinol Metab Clin North Am. 2021; 50(1):57-69.

5. Chang S, Dunaif A. Diagnosis of polycystic ovary syndrome: which criteria to use and when? Endocrinol Metab Clin North Am. 2021;50(1):11-23.

6. Aly JM, Decherney AH. Lifestyle modifications in PCOS. Clin Obstet Gynecol. 2021;64(1):83-9.

7. Saei Ghare Naz M, Ramezani Tehrani F, Behroozi-Lak T, Mohammadzadeh F, Kholosi Badr F, Ozgoli G. Polycystic ovary syndrome and pelvic floor dysfunction: a narrative review. Res Rep Urol. 2020;12:179-85.

8. Osibogun O, Ogunmoroti O, Michos ED. Polycystic ovary syndrome and cardiometabolic risk: opportunities for cardiovascular disease prevention. Trends Cardiovasc Med. 2020;30(7):399-404.

9. Joham AE, Palomba S, Hart R. Polycystic ovary syndrome, obesity, and pregnancy. Semin Reprod Med. 2016;34(2):93-101.

10. Lonnebotn M, Natvig GK, Benediktsdottir B, Burgess JA, Holm M, Jogi R, Lindberg E, Macsali F, Schlunssen V, Skulstad SM, et al. Polycystic ovary syndrome, body mass index and hypertensive disorders in pregnancy. Pregnancy Hypertens. 2018;11:32-7.

11. Joham AE, Boyle JA, Zoungas S, Teede HJ. Hypertension in reproductiveaged women with polycystic ovary syndrome and association with obesity. Am J Hypertens. 2015;28(7):847-51.

12. Pinola P, Puukka K, Piltonen TT, Puurunen J, Vanky E, Sundstrom-Poromaa I, Stener-Victorin E, Linden Hirschberg A, Ravn P, Skovsager Andersen M, et al. Normo- and hyperandrogenic women with polycystic ovary syndrome exhibit an adverse metabolic profile through life. Fertil Steril. 2017;107(3): 788-795 e782.

13. Schneider D, Gonzalez JR, Yamamoto M, Yang J, Lo JC. The Association of Polycystic Ovary Syndrome and Gestational Hypertensive Disorders in a Diverse Community-Based Cohort. J Pregnancy. 2019;2019:9847057.

14. Lizneva D, Kirubakaran R, Mykhalchenko K, Suturina L, Chernukha G, Diamond MP, Azziz R. Phenotypes and body mass in women with polycystic ovary syndrome identified in referral versus unselected populations: systematic review and meta-analysis. Fertil Steril. 2016;106(6): 1510-1520 e1512.

15. Escobar-Morreale HF. Polycystic ovary syndrome: definition, aetiology, diagnosis and treatment. Nat Rev Endocrinol. 2018;14(5):270-84.

16. Pena AS, Witchel SF, Hoeger KM, Oberfield SE, Vogiatzi MG, Misso M, Garad $\mathrm{R}$, Dabadghao P, Teede H. Adolescent polycystic ovary syndrome according to the international evidence-based guideline. BMC Med. 2020;18(1):72.

17. Group of Hypertension in Pregnancy BoOaG, Chinese Medical Association. Guidelines for the diagnosis and treatment of hypertension in pregnancy. Chin J Obstet Gynecol. 2015:50(10):721-8.

18. Ganie MA, Vasudevan V, Wani IA, Baba MS, Arif T, Rashid A. Epidemiology, pathogenesis, genetics \& management of polycystic ovary syndrome in India. Indian J Med Res. 2019;150(4):333-44.

19. Ortiz-Flores AE, Luque-Ramirez M, Escobar-Morreale HF. Polycystic ovary syndrome in adult women. Med Clin (Barc). 2019;152(11):450-7.

20. Dumesic DA, Oberfield SE, Stener-Victorin E, Marshall JC, Laven JS, Legro RS. Scientific Statement on the Diagnostic Criteria, Epidemiology, Pathophysiology, and Molecular Genetics of Polycystic Ovary Syndrome. Endocr Rev. 2015;36(5):487-525.

21. Ali AT. Polycystic ovary syndrome and metabolic syndrome. Ceska Gynekol. 2015;80(4):279-89.

22. Belenkaia LV, Lazareva LM, Walker W, Lizneva DV, Suturina LV. Criteria, phenotypes and prevalence of polycystic ovary syndrome. Minerva Ginecol. 2019;71(3):211-23.

23. Neven ACH, Laven J, Teede HJ, Boyle JA. A summary on polycystic ovary syndrome: diagnostic criteria, prevalence, clinical manifestations, and management according to the latest international guidelines. Semin Reprod Med. 2018;36(1):5-12.

24. Xiaohui T, Haiyan L. Risk factors and risk model establishment of hypertension during pregnancy in patients with polycystic ovary syndrome in late pregnancy. Chin J Sex. 2020;29(5):64-8. 
25. Mu L, Zhao Y, Li R, Lai Y, Chang HM, Qiao J. Prevalence of polycystic ovary syndrome in a metabolically healthy obese population. Int J Gynaecol Obstet. 2019;146(2):164-9.

26. Lee I, Cooney LG, Saini S, Smith ME, Sammel MD, Allison KC, Dokras A Increased risk of disordered eating in polycystic ovary syndrome. Fertil Steril. 2017;107(3):796-802

27. Mokhlesi B, Scoccia B, Mazzone T, Sam S. Risk of obstructive sleep apnea in obese and nonobese women with polycystic ovary syndrome and healthy reproductively normal women. Fertil Steril. 2012;97(3):786-91.

28. Teede HJ, Joham AE, Paul E, Moran LJ, Loxton D, Jolley D, Lombard C Longitudinal weight gain in women identified with polycystic ovary syndrome: results of an observational study in young women. Obesity (Silver Spring). 2013;21(8):1526-32.

29. Het TD, Teede HJ, de Courten B, Loxton D, Real FG, Moran LJ, Joham AE: Asthma in reproductive-aged women with polycystic ovary syndrome and association with obesity. Eur Respir J 2017, 49(5): 1601334.

30. Sim SY, Chin SL, Tan JL, Brown SJ, Cussons AJ, Stuckey BG. Polycystic ovary syndrome in type 2 diabetes: does it predict a more severe phenotype? Fertil Steril. 2016;106(5):1258-63.

31. Joham AE, Nanayakkara N, Ranasinha S, Zoungas S, Boyle J, Harrison CL, Forder P, Loxton D, Vanky E, Teede HJ. Obesity, polycystic ovary syndrome and breastfeeding: an observational study. Acta Obstet Gynecol Scand. 2016;95(4):458-66

32. Sheng Y, Lu G, Liu J, Liang X, Ma Y, Zhang X, Zhang S, Sun Y, Sun Y, Chen $W$, et al. Effect of body mass index on the outcomes of controlled ovarian hyperstimulation in Chinese women with polycystic ovary syndrome: a multicenter, prospective, observational study. J Assist Reprod Genet. 2017; 34(1):61-70.

33. Sterling L, Liu J, Okun N, Sakhuja A, Sierra S, Greenblatt E. Pregnancy outcomes in women with polycystic ovary syndrome undergoing in vitro fertilization. Fertil Steril. 2016;105(3):791-797 e792.

34. Lane-Cordova AD, Tedla YG, Carnethon MR, Montag SE, Dude AM, Rasmussen-Torvik LJ. Pre-pregnancy blood pressure and body mass index trajectories and incident hypertensive disorders of pregnancy. Pregnancy Hypertens. 2018;13:138-40.

35. Stovall DW, Bailey AP, Pastore LM. Assessment of insulin resistance and impaired glucose tolerance in lean women with polycystic ovary syndrome. J Womens Health (Larchmt). 2011;20(1):37-43.

36. Liang $P$, Xi L, Shi J, Li W, Zhao S, Deng Y, Wang R, Sun Y, Gu B, Yuan L, et al. Prevalence of polycystic ovary syndrome in Chinese obese women of reproductive age with or without metabolic syndrome. Fertil Steril. 2017; 107(4):1048-54.

37. Stepto NK, Cassar S, Joham AE, Hutchison SK, Harrison CL, Goldstein RF, Teede HJ. Women with polycystic ovary syndrome have intrinsic insulin resistance on euglycaemic-hyperinsulaemic clamp. Hum Reprod. 2013;28(3): 777-84

38. Tay CT, Teede HJ, Hill B, Loxton D, Joham AE. Increased prevalence of eating disorders, low self-esteem, and psychological distress in women with polycystic ovary syndrome: a community-based cohort study. Fertil Steril. 2019;112(2):353-61.

39. Schmiegelow MD, Andersson C, Kober L, Andersen SS, Norgaard ML, Jensen TB, Gislason G, Berger SM, Torp-Pedersen C. Associations between body mass index and development of metabolic disorders in fertile women-a nationwide cohort study. J Am Heart Assoc. 2014;3(2): e000672.

40. Glintborg D, Rubin KH, Nybo M, Abrahamsen B, Andersen M. Cardiovascular disease in a nationwide population of Danish women with polycystic ovary syndrome. Cardiovasc Diabetol. 2018;17(1):37.

41. Kim JJ, Choi YM, Hong MA, Kim JM, Hwang SS, Lee GH, Chae SJ, Hwang KR, Yoon $\mathrm{SH}, \mathrm{Kim} \mathrm{SH}$. Gene dose effect between a fat mass and obesityassociated polymorphism and body mass index was observed in Korean women with polycystic ovary syndrome but not in control women. Fertil Steril. 2014;102(4):1143-1148 e1142.

42. Kawakita T, Downs SK, Franco S, Ghofranian A, Thomas A: Interpregnancy body mass index change and risk of hypertensive disorders in pregnancy. J Matern Fetal Neonatal Med 2020;35:1-6.

43. Nielsen JH, Birukov A, Jensen RC, Kyhl HB, Jorgensen JS, Andersen MS, Glintborg D. Blood pressure and hypertension during pregnancy in women with polycystic ovary syndrome: Odense Child Cohort. Acta Obstet Gynecol Scand. 2020;99(10):1354-63.
44. Taskin MI, Bulbul E, Adali E, Hismiogullari AA, Inceboz U. Circulating levels of obestatin and copeptin in obese and nonobese women with polycystic ovary syndrome. Eur J Obstet Gynecol Reprod Biol. 2015;189:19-23.

45. Kakoly NS, Earnest A, Moran LJ, Teede HJ, Joham AE. Group-based developmental BMI trajectories, polycystic ovary syndrome, and gestational diabetes: a community-based longitudinal study. BMC Med. 2017;15(1):195.

46. West S, Lashen H, Bloigu A, Franks S, Puukka K, Ruokonen A, Jarvelin MR, Tapanainen JS, Morin-Papunen L. Irregular menstruation and hyperandrogenaemia in adolescence are associated with polycystic ovary syndrome and infertility in later life: Northern Finland Birth Cohort 1986 study. Hum Reprod. 2014;29(10):2339-51.

47. Shufelt C, LeVee A: Hormonal Contraception in Women With Hypertension. JAMA. 2020;8:22-9.

48. DeNicola N, Grossman D, Marko K, Sonalkar S, Butler Tobah YS, Ganju N, Witkop CT, Henderson JT, Butler JL, Lowery C. Telehealth Interventions to Improve Obstetric and Gynecologic Health Outcomes: A Systematic Review. Obstet Gynecol. 2020;135(2):371-82.

49. Liu H, Yao J, Wang W, Zhang D. Association between duration of oral contraceptive use and risk of hypertension: A meta-analysis. J Clin Hypertens (Greenwich). 2017;19(10):1032-41.

50. Carmine L. Contraception for Adolescents with Medically Complex Conditions. Curr Probl Pediatr Adolesc Health Care. 2018:48(12):345-57.

51. Long ME, Faubion SS, MacLaughlin KL, Pruthi S, Casey PM. Contraception and hormonal management in the perimenopause. J Womens Health (Larchmt). 2015;24(1):3-10.

52. Lauring JR, Lehman EB, Deimling TA, Legro RS, Chuang CH: Combined hormonal contraception use in reproductive-age women with contraindications to estrogen use. Am J Obstet Gynecol 2016, 215(3):330 e331-337.

53. Colatrella A, Braucci S, Festa C, Bianchi P, Fallucca F, Mattei L, Trappolini M, Napoli A. Hypertensive disorders in normal/over-weight and obese type 2 diabetic pregnant women. Exp Clin Endocrinol Diabetes. 2009;117(8):373-7.

54. Amiri M, Ramezani Tehrani F, Behboudi-Gandevani S, Bidhendi-Yarandi R, Carmina E. Risk of hypertension in women with polycystic ovary syndrome: a systematic review, meta-analysis and meta-regression. Reprod Biol Endocrinol. 2020;18(1):23.

\section{Publisher's Note}

Springer Nature remains neutral with regard to jurisdictional claims in published maps and institutional affiliations.
Ready to submit your research? Choose BMC and benefit from:

- fast, convenient online submission

- thorough peer review by experienced researchers in your field

- rapid publication on acceptance

- support for research data, including large and complex data types

- gold Open Access which fosters wider collaboration and increased citations

- maximum visibility for your research: over $100 \mathrm{M}$ website views per year

At BMC, research is always in progress.

Learn more biomedcentral.com/submissions 